\title{
Analysis of the obesity gene FTO in 14,803 type 1 diabetes cases and controls
}

\author{
S. F. Field • J. M. M. Howson • N. M. Walker • \\ D. B. Dunger $\cdot$ J. A. Todd
}

Received: 27 April 2007 / Accepted: 5 June 2007 / Published online: 27 July 2007

(C) Springer-Verlag 2007

Keywords $F T O$. Genetic association · Obesity .

Type 1 diabetes

\author{
Abbreviations \\ MAF minor allele frequency \\ OR odds ratio \\ SNP single nucleotide polymorphism
}

To the Editor: Early weight gain in infancy, high nutrient intake and large body size in childhood have been associated with type 1 diabetes [1-4]. It has also been suggested that childhood weight gain accounts for the trend towards an earlier age at onset observed in type 1 diabetes [5]. The fat mass and obesity associated gene $(F T O)$ region on chromosome $16 \mathrm{q} 12$ has recently been found to contribute to the risk of obesity [6]. Although the single nucleotide polymorphism (SNP) rs9939609 (T>A) in the fat mass and obesity associated gene (FTO) was originally found to be associated with type 2 diabetes [odds ratio (OR) 1.27, 95\%

S. F. Field · J. M. M. Howson · N. M. Walker · J. A. Todd $(\bowtie)$ Juvenile Diabetes Research Foundation/Wellcome Trust Diabetes and Inflammation Laboratory, Cambridge Institute for Medical Research, University of Cambridge, Wellcome Trust/MRC

Building, Addenbrooke's Hospital,

Hills Road,

Cambridge CB2 0XY, UK

e-mail: John.Todd@cimr.cam.ac.uk

D. B. Dunger

Department of Paediatrics, University of Cambridge,

Addenbrooke's Hospital,

Cambridge, UK
CI 1.16-1.37; $p=5 \times 10^{-8}$ ], this association was shown to be entirely mediated by the effect of FTO on obesity [6]. The FTO polymorphism was associated with an increased BMI of $\sim 0.2 \mathrm{~kg} / \mathrm{m}^{2}$ per allele in children aged 7 years $\left(p=3 \times 10^{-5}\right)$ up to an increase of $\sim 0.4 \mathrm{~kg} / \mathrm{m}^{2}$ at age 11 years [6]. The effect of the FTO gene variant on obesity, in particular on childhood obesity, makes it a good candidate to test whether a genetic predisposition to increased weight gain affects susceptibility to type 1 diabetes.

We analysed the FTO SNP rs9939609 in a cohort of 14,803 British type 1 diabetes subjects and controls of white ethnicity. The type 1 diabetes case group consists of 7,463 participants from the Juvenile Diabetes Research Foundation/Wellcome Trust Diabetes and Inflammation Laboratory's Genetic Resource Investigating Diabetes study (http://www-gene.cimr.cam.ac.uk/todd/, last accessed in June 2007) and 184 from the Oxford Regional Prospective Study [7]. All of the type 1 diabetes group were aged under 17 years at diagnosis. The control group, which is geographically matched to the case group, consists of 5,655 individuals from the British 1958 Birth Cohort (http://www.b58cgene.sgul.ac.uk/index.php, last accessed in June 2007) and 1,501 individuals from the UK Blood Services repository [8], all of whom are of white ethnicity. The controls include $95 \%$ of the 2,855 controls used by the Wellcome Trust Case-Control Consortium http://www. wtccc.org.uk/, last accessed in June 2007) [8], as reported by Frayling et al. [6]. Genotyping was carried out using the TaqMan 5' nuclease assay (Applied Biosystems, Warrington, UK). Given the reported minor allele (A) frequency (MAF) of 0.40 [6], our study had $99 \%$ power to exclude an effect with an OR $>1.14$ at $\alpha=10^{-3}$. This $\alpha$ level can be considered appropriate assuming that the prior information concerning obesity being a factor in type 1 diabetes 
Table 1 Association of the FTO gene SNP rs9939609 with type 1 diabetes in 7,647 type 1 diabetic individuals and 7,156 controls

\begin{tabular}{llllc}
\hline & $\begin{array}{l}\text { Cases } \\
n(\%)\end{array}$ & $\begin{array}{l}\text { Controls } \\
n(\%)\end{array}$ & OR & 95\% CI \\
\hline $\begin{array}{llll}\text { Alleles } \\
\text { T }\end{array}$ & & & & \\
A & $9,196(0.60)$ & $8,679(0.61)$ & 1.00 & $0.26^{\mathrm{b}}$ \\
Genotypes & $6,098(0.40)$ & $5,633(0.39)$ & 1.03 & $0.98-1.08$ \\
TT & & & & $($ reference $)$ \\
TA & $2,761(0.36)$ & $2,633(0.37)$ & 1.00 & $0.96-1.11$ \\
AA & $3,674(0.48)$ & $3,413(0.48)$ & 1.03 & $0.95-1.16$ \\
\hline
\end{tabular}

We assumed a multiplicative model of effect.

a $2 \times$ number of subjects

${ }^{\mathrm{b}}$ Significance of difference between two alleles

${ }^{c}$ Significance of difference between three genotypes

is true. Alternatively, assuming no prior information, on a genome-wide level, in which case an $\alpha$ level of $10^{-8}$ would be appropriate, our study has $99 \%$ power to exclude an effect with an $\mathrm{OR}>1.2$. In this sample set we obtained a MAF of 0.39 for the A allele of rs9939609 (Table 1). The genotype distribution for this SNP was consistent with Hardy-Weinberg equilibrium in both the controls and the cases $(p=0.94)$. We found no evidence for an association between FTO and type 1 diabetes (OR 1.03, 95\% CI 0.98 $1.08 ; p=0.26$; Table 1$)$. We tested whether there was any association between FTO and the age at diagnosis of type 1 diabetes. In this test we treated age at diagnosis as a continuous variable and found no association $(p=0.85)$. We also analysed the frequencies of the rs 9939609 genotypes in children stratified into the following groups according to age at diagnosis of type 1 diabetes: $0-5$ years, $5-10$ years and $>10$ years. The frequency of the AA genotype (the genotype most strongly associated with obesity) was almost identical (0.16) in all three age groups (Table 2).

In this study we found that the FTO gene polymorphism rs9939609, which increases the risk of childhood obesity and type 2 diabetes [6], does not alter susceptibility to type 1 diabetes nor the age at which type 1 diabetes occurs, to any measurable extent, in this British population. Our results

Table 2 Genotype frequency of the SNP rs9939609 in type 1 diabetic individuals stratified according to age at diagnosis

\begin{tabular}{llll}
\hline Genotype & \multicolumn{3}{c}{ Age at diagnosis (years) } \\
\cline { 2 - 4 } & $\leq 5$ & \multicolumn{1}{c}{$5<$ age $\leq 10$} & $>10$ \\
\hline TT & $920(0.36)$ & $859(0.37)$ & $781(0.36)$ \\
TA & $1,203(0.48)$ & $1,117(0.48)$ & $1,036(0.48)$ \\
AA & $399(0.16)$ & $365(0.16)$ & $345(0.16)$ \\
\hline
\end{tabular}

Values are presented as $n(\%)$ do not disprove the findings associating weight gain with type 1 diabetes [4], but indicate that FTO-mediated weight gain does not predispose individuals to type 1 diabetes as it does for type 2 diabetes.

Note added in proof The SNP rs9939609 is in strong LD $\left(r^{2}=0.93-1.0\right)$ with the three most associated FTO SNPs, rs17817449, rs371812 and rs1421085 in the study published recently by Dina C, Meyre D, Gallina S et al (2007) Variation in FTO contributes to childhood obesity and severe adult obesity. Nat Genet 39:724-726.

Acknowledgements This work was funded by the Wellcome Trust, the Juvenile Diabetes Research Foundation and the Medical Research Council. We acknowledge use of DNA from the British 1958 Birth Cohort collection (D. Strachan, P. Burton, S. Ring, R. Jones, W. McArdle and M. Pembrey), funded by the Medical Research Council grant G0000934 and Wellcome Trust grant $068545 / Z / 02$. We also thank B. Widmer and H. Stevens and the JDRF/WT Diabetes and Inflammation Laboratory DNA team for collecting and preparing the type 1 diabetes case samples, and $\mathrm{J}$. Hafler for help with genotyping.

Duality of interest The authors declare that there is no duality of interest associated with this manuscript.

\section{References}

1. Johansson C, Samuelsson U, Ludvigsson J (1994) A high weight gain early in life is associated with an increased risk of type 1 (insulin-dependent) diabetes mellitus. Diabetologia 37: 91-94

2. Pundziute-Lycka A, Persson LA, Cedermark G et al (2004) Diet, growth, and the risk for type 1 diabetes in childhood: a matched case-referent study. Diabetes Care 27:2784-2789

3. Brown M, Ahmed ML, Clayton KL et al (1994) Growth during childhood and final height in type 1 diabetes. Diabet Med 11: 182-187

4. The EURODIAB Substudy 2 Study Group (2002) Rapid early growth is associated with increased risk of childhood type 1 diabetes in various European populations. Diabetes Care 25:1755-1760 
5. Virtanen SM, Knip M (2003) Nutritional risk predictors of beta cell autoimmunity and type 1 diabetes at a young age. Am J Clin Nutr 78:1053-1067

6. Frayling TM, Timpson NJ, Weedon MN et al (2007) A common variant in the FTO gene is associated with body mass index and predisposes to childhood and adult obesity. Science 316:889-894
7. Amin R, Bahu TK, Widmer B et al (2005) Longitudinal relation between limited joint mobility, height, insulin-like growth factor 1 levels, and risk of developing microalbuminuria: the Oxford Regional Prospective study. Arch Dis Child 90:1039-1044

8. Wellcome Trust Case Control Consortium (2007) Genome-wide association study of 14,000 cases of seven common diseases and 3,000 shared controls. Nature 447:661-678 